\title{
Student Seating Position and Their Academic Performance in Computer Science Major
}

\author{
Observational Study and Student Perspective
}

\author{
Gisela Kurniawati ${ }^{1}$, Oscar Karnalim ${ }^{2}$, Setia Budi ${ }^{3}$ \\ ${ }^{1,2,3}$ Faculty of Information Technology, Maranatha Christian University, Bandung, Indonesia \\ 1' gisela.kurniawati@maranatha.ac.id, ${ }^{2}$ oscar.karnalim@maranatha.ac.id, ${ }^{3}$ setia.budi@maranatha.ac.id
}

Accepted on August 25, 2020

Approved on February 11, 2021

\begin{abstract}
A number of studies regarding the correlation between student seating position and their academic performance have been conducted. However, only a few of them focusing on computer science major, which is argued to be unique in terms of teaching style and classroom layout; as the discipline puts more emphasise on hands on activity like programming, system and network configuration. Further, among those works focusing on that major, none of them specifically address undergraduate students. This paper presents an observational study involving 426 computer science undergraduate students. The study covers student activity over one academic semester. A questionnaire survey measuring student awareness about that correlation in their seating preference was also performed, with 126 students as the respondents. In general, the correlation only exists on some circumstances like student major and lecture time. Further, the seating preference can be driven by the awareness of that correlation with some motivating factors like friends, whiteboard position, and personal habit. Per occasion, it is suggested to analyse the class circumstances and the student motivating factors prior performing further actions.
\end{abstract}

Index Terms-academic performance; computing education; observational study; seating position; survey instrument

\section{INTRODUCTION}

Within academic institutions (including Indonesia), there is a common assumption that academic performance of a student is influenced by their seating position in a classroom [1, 2]. Front row seating is often classified as seating positions for high performer students, whereas rear seating preferences are associated with low performing students.

A number of studies measuring and investigating the correlation between students seating position and their academic performance have been conducted, some of the notable works are reported in $[3,4,5,6,7$, 8]. Although majority of the studies confirm the existence of the correlation, some studies argue that the correlation is relatively weak [7, 8]. One of the possible reasons is that both seating position and academic performance are influenced by numerous factors, including teaching material, teaching style, demographic, learning style, learning motivation, and available seat.

Two studies investigating that correlation $[1,3]$ are focused on students in computer science major which is argued to be unique in terms of teaching style and classroom layout; as the discipline puts more emphasise on hands on activity (e.g., programming, system and network configuration) $[9,10,11]$. The first study focuses on postgraduate students [3] while another focuses on the combination of undergraduate and postgraduate students [1]. However, none of them are primarily focused on undergraduate students though they cover the largest proportion of university students.

In response to the aforementioned gap, this paper observes the correlation among undergraduate computer science major. To the best of our knowledge, this is the first one of its type, and the findings are expected to complement the two existing works [1, 3]. Student awareness about that correlation in selecting their seating position is also observed to suggest further necessary actions. If the correlation exist and the students are already aware about it, therefore no need to take further action. This also applies in the situation where the correlation does not exist and the students are not aware about it. In contrast, if the correlation exist and the students are unaware about it, an awareness campaign is required. A counter awareness campaign is also required if such a correlation does not exist but the students falsely perceived that their seating position has impact on their academic performance.

Our research questions are:

RQ1 Is there any correlation between student seating position and their academic performance (SPAP correlation)?

RQ2 Do student seating position driven by the awareness of SP-AP correlation? 


\section{RELATED WORKS}

Student seating position in a classroom is often associated with student's motivation in attending the lecture $[12,13,14,15]$ where front-seated students are perceived as students with higher motivation when compared to rear-seated students. Some even may jump into a conclusion that high performer students tend to seat in front rows whereas low performer students prefer rear rows. Such assumption, if not handled properly, might unintentionally lead to a bias perspective among the lecturers [1, 16]. A lecturer may interact or make eye contact limited to the frontseated students only, neglecting the rest of the class. This could demotivate other students in learning, as interaction and contact could play a significant role in maintaining student engagement in a classroom $[1,2$, $4,17]$.

A number of studies have been conducted to investigate the correlation between students seating position and their academic performance $[1,2,3,4,5$, $6,16]$. These studies confirm that seating position correlates with students' academic performance. However, even though they are all agreed that such correlation exist, their arguments are divided into two groups. First, those who argue that high performer students prefer front row position therefore such correlation exist $[2,16]$. Second, those who argue that students' academic performance is influenced by their seating position $[1,3,4,5]$. Factors such as better vision, better hearing of the lecture, better attention and greater eye contact are identified as favouring factors which benefit students who are sitting at the front rows [1, 4]. In contrast, other study reported that student performance is not significantly influenced by seating position $[7,8]$. This case could be found in a smaller classroom size (compared to the number of students); clearly not every student could occupy the front rows.

In our literature survey, we also identified other notable works related to students seating position in a classroom. The study reported in [18] suggested that students seated at the front experience less daydreaming. Their study also indicated that the increase in daydreaming frequency leads to poorer academic performance. Classroom seating structure is formalised in [19], where seating position in a classroom is classified into four zones (e.g., front, rear, central, and side). The structure is aimed to promote consistency among studies related to seating position in a classroom. Lecturer perceptions of students may also be influenced by student seating choices, as reported in [16]. The study raises a concern that the seating position could affect the formation of lecturers' evaluative judgements toward their students. A study presented in [20] utilises the seating position to identify plagiarism on in-class individual programming assignment.
The majority of the studies in investigating the correlation between student seating position/arrangement and academic performance were conducted in the context of primary and secondary schools [21, 22, 23]. However, there is also a growing number to replicate a similar study at the university level. A study reported in [1] was conducted in engineering and computer science department at a university in Spain. For data collection purposes, they employed a software tool to automate the process. The study was mainly focusing on three parameters: average mark of a chair (i.e., seating position), times a chair was used, and times a chair was used by students who gave up the course. Their investigation lead to a conclusion that seating position in a classroom influences academic performance. Another notable investigation related to seating position at the university level was reported in [3]. Their study was conducted over a period of twelve weeks in a programming course.

\section{METHOD}

Two research questions discussed in the introduction (RQ1 and RQ2) were addressed in twofold. RQ1 was answered via an observational study involving the seating position and the academic performance of 426 computer science undergraduate students, collected within one academic semester. RQ2 was answered based on a questionnaire survey, responded by 126 computer science undergraduate students.

\section{A. Addressing RQ1: The Observational Study}

To address RQ1, whether there is any SP-AP correlation, an observational study was performed on 426 computer science students who were enrolled in the department of the first author from August to December 2017. The students came from two undergraduate majors - Information Technology (IT) and Information System (IS) - with total number of students 311 and 115 respectively. Their enrolment years are ranged from 2011 to 2017 but most of them are from 2014 to 2017. Over the period of one academic semester, student seating position and their academic performance were recorded. We focused our observation only on the seating position in the laboratories. Such a decision was made considering most courses in our faculty are delivered in the laboratories, including the lecture session. In total, there were 92 class sessions delivered in twelve different laboratories (denoted as LAB-01 to LAB-12). As suggested in [19], the seating position was mapped into four regions: Front, Centre, Side, and Rear. The mapping for each laboratory can be seen on Fig. 1, while the number of teaching sessions can be seen on Table I. 


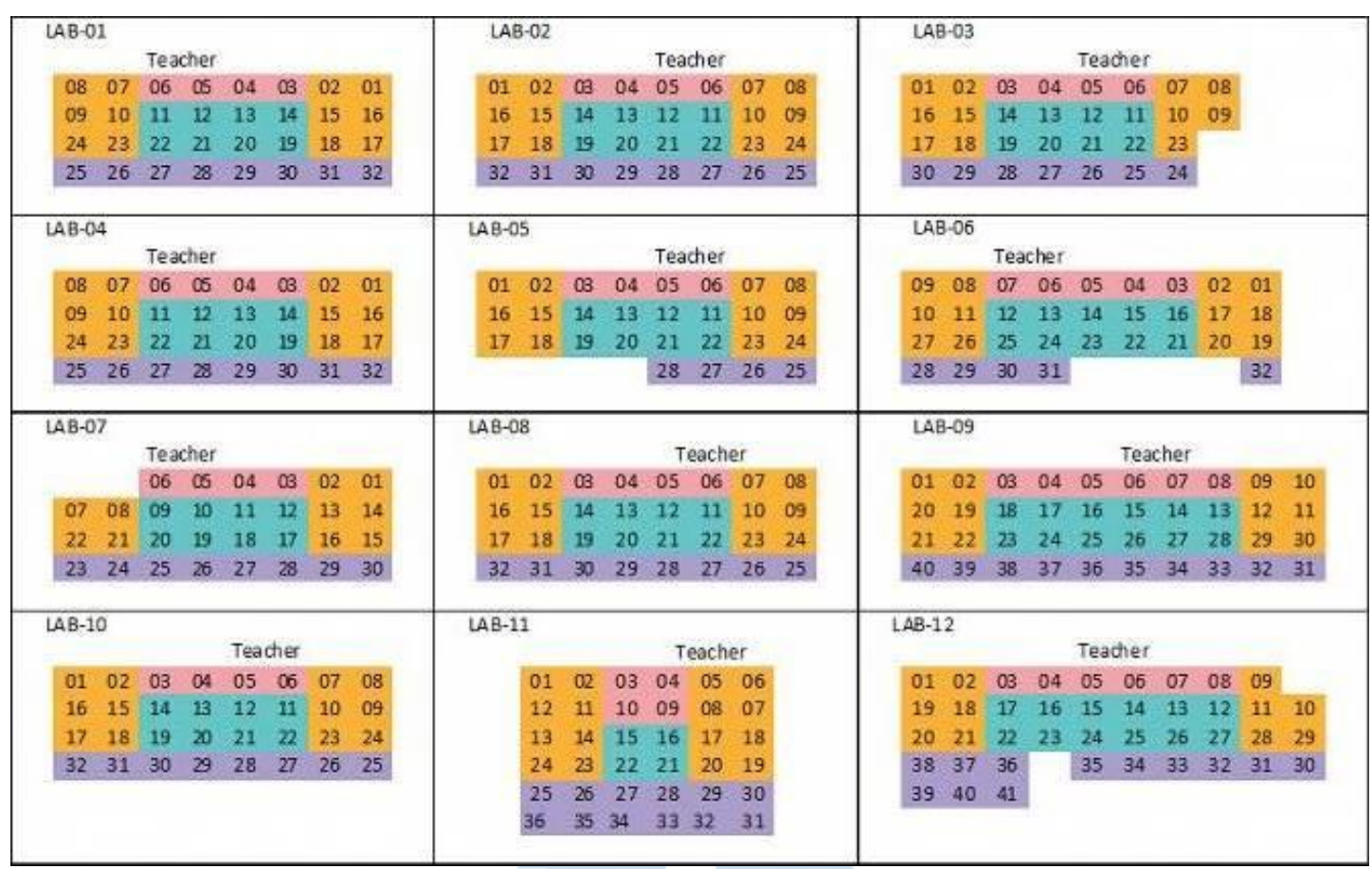

Fig. 1. The mapping of seating position in laboratories. Front seats are pink-coloured; centre seats are blue-coloured; side seats are orangecoloured; and rear seats are purple-coloured

TABLE I. Number OF TeACHING SESSIONS PER LABORATORY

\begin{tabular}{|l|l|l|l|}
\hline Laboratory & IT Sessions & IS Sessions & Total \\
\hline Lab-01 & 11 & 2 & 13 \\
\hline Lab-02 & 7 & 0 & 7 \\
\hline Lab-03 & 0 & 0 & 0 \\
\hline Lab-04 & 6 & 6 & 12 \\
\hline Lab-05 & 8 & 2 & 10 \\
\hline Lab-06 & 9 & 0 & 9 \\
\hline Lab-07 & 0 & 13 & 13 \\
\hline Lab-08 & 5 & 2 & 7 \\
\hline Lab-09 & 6 & 1 & 7 \\
\hline Lab-10 & 2 & 3 & 5 \\
\hline Lab-11 & 2 & 0 & 2 \\
\hline Lab-12 & 7 & 0 & 7 \\
\hline Total & 63 & 29 & 92 \\
\hline
\end{tabular}

In this study, we measure academic performance for each student based on their achievement (i.e., score or mark) in accomplishing their mid-term exam, final exam, and course assignment. We are also taking account the aggregate score (final score) which calculated based on the mid-term exam, final exam, and assignment with the weight of $25 \%, 25 \%$, and $50 \%$ respectively.

We divided our observational study into five stages (as illustrated in Fig. 2). At first, we limited our observation only within the courses which final score is yielded from in-class activities. Few courses which did not match this criterion, such as thesis, Certified
System Administrator). Secondly, three kinds of data were collected: student internship, and certificationbased courses (e.g., Certified Ethical Hacking, RedHat seating position, student grades, and seating layout in each laboratory (i.e., seating layout has been fixed for the semester). Student seating position was recorded in a paper format as part of student attendance recording system applied in our department. Fig. 3 shows the paper sheets which were used to record student seating position in this study; each sheet holds a record of weekly students seating position in each course that they were enrolled in. The data was digitised at the third stage.

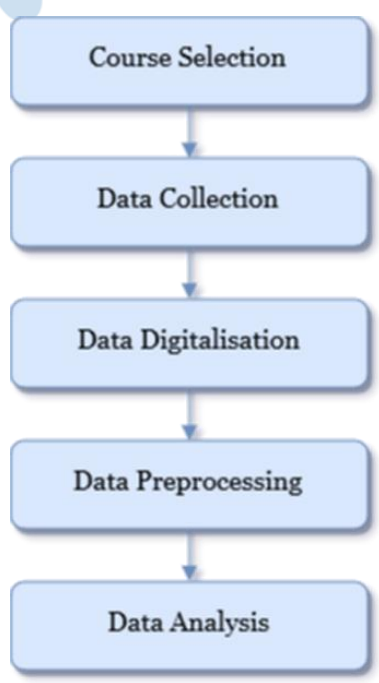

Fig. 2. The observational study was performed with five consecutive stages. It started with course selection and finished with data analysis. 


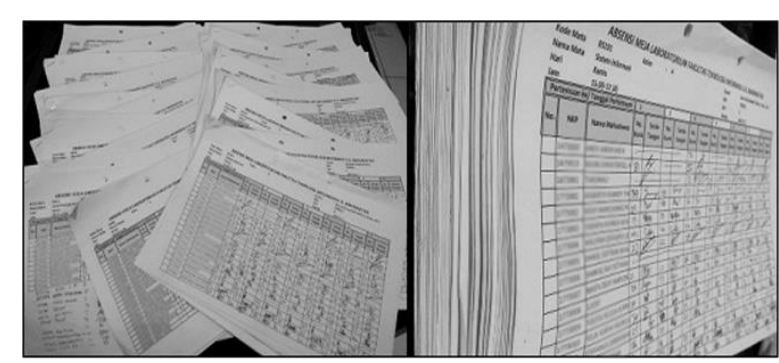

Fig. 3. Physical paper sheets depicting student seating position Horizontal axis represents sessions while the vertical one represents student IDs. Each cell contains a number representing a desk ID where a student is seated for a particular session.

At the fourth stage, the data was then converted to a particular format for analysis. Each student per course was converted into one data entry, representing student seating position for one semester and their academic scores. It is possible that occasionally, some students did not choose their seating position based on their preference. For example, a student who was regularly seated at a front row might be seated at the back when they are late (as the front row had been taken by other student). Hence, to exclude such cases from consideration, the seating position was replaced with three fields. fh and eh refer to the most frequent seating region for the first and second half semester respectively. $\mathrm{f}$ is similar to the first two except that it covers the whole semester. In total, this phase results in 1.546 data entries.

Finally, the analysis was then performed by correlating student academic performance with their seating position. Mid test score was correlated with student seating position before the test (from week one to week seven). Final test score was correlated with student seating position between the mid test and the final test (from week eight to week fourteen). Assignment and final score were correlated with student seating position for the whole semester.

Three dimensions are considered for the analysis in this study (i.e., major, teaching type, teaching session time). Major refers to whether the students came from IT or IS major. Teaching type refers to whether the session is mostly about lecture session or lab session. Typically, the former occurs on non-programming courses while the latter occurs on their counterparts. Teaching session time refers to when the session was conducted. To reduce the variants, the time was categorised to four groups which details can be seen on Table II; all class sessions were aligned to one of these groups based on the largest session proportion.

TABLE II. TEACHING SEASON TIME

\begin{tabular}{|l|l|l|l|}
\hline Group Name & Start Time & End Time & $\begin{array}{l}\text { Number of } \\
\text { Sessions }\end{array}$ \\
\hline Morning & $07: 00$ & $12: 00$ & 46 \\
\hline Afternoon & $12: 00$ & $15: 00$ & 19 \\
\hline
\end{tabular}

\begin{tabular}{|l|l|l|l|}
\hline Late Afternoon & $15: 00$ & $17: 30$ & 23 \\
\hline Night & $17: 30$ & $21: 00$ & 4 \\
\hline
\end{tabular}

These dimensions are converted to filtering scenarios, starting with one dimension at a time (the most general) to all dimensions (the most specific) [24]. The analysis would not be continued with more dimensions once interesting findings are shown; as general findings are preferred to the specific ones. For each filtering scenario, the data was analysed through three graphs:

- Box plot is utilised by considering seating regions as the horizontal axis and student academic scores as the vertical one. It visualises the tendency of seating regions to be correlated with a particular student grade range. An example of box plot can be seen in Fig. 4.

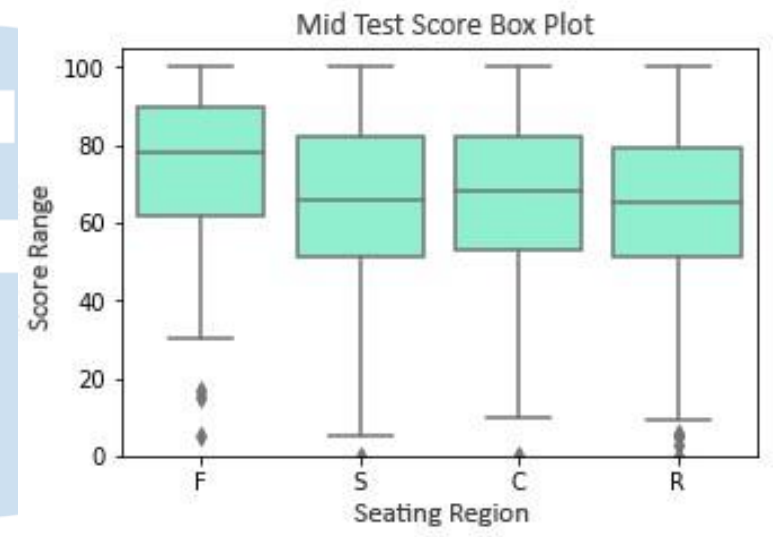

Fig. 4. A sample box plot for mid test score. Horizontal axis represents the seating regions while the vertical one represents the score.

- Stacked bar chart is used in twofold. At first, student academic scores are grouped to three categories: high, medium, and low. High means that the score is higher or equal to 73 (a minimum threshold to get $\mathrm{B}+$ or $\mathrm{A}$ in our faculty). Average means that the score is higher or equal to 55 but not in High category (which depicts $\mathrm{C}, \mathrm{C}+$, and $\mathrm{B}$ grades). Low refers to the score that is not in High or Medium range. Secondly, by considering seating regions as the horizontal axis, the chart is generated. This visualises the numbers of student academic score categories per seating region; where the highest and lowest value can be further analysed. Fig. 5 shows an example of stacked bar chart. 


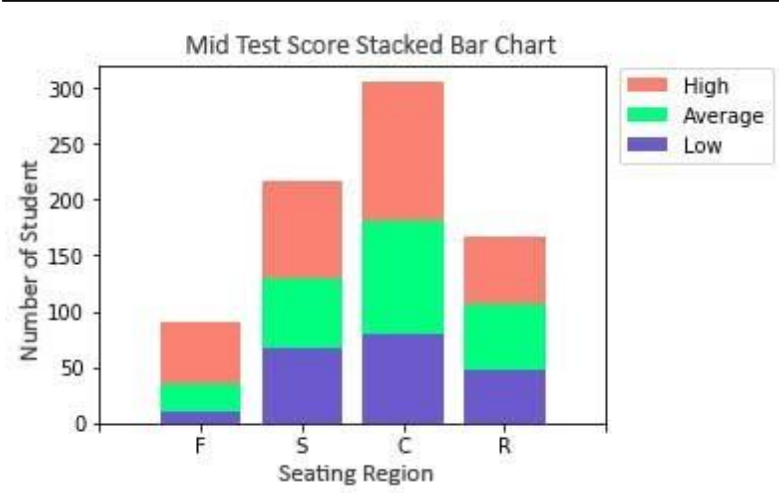

Fig. 5. A sample stacked bar chart for mid test score. Horizontal axis represents the seating regions while the vertical one represents the score.

- Stacked bar chart with relative frequency is similar to the stacked bar chart except that the frequencies are treated as percentage. It aims to see the largest or smallest proportion of student academic score categories per seating region. An example of this can be seen in Fig. 6.

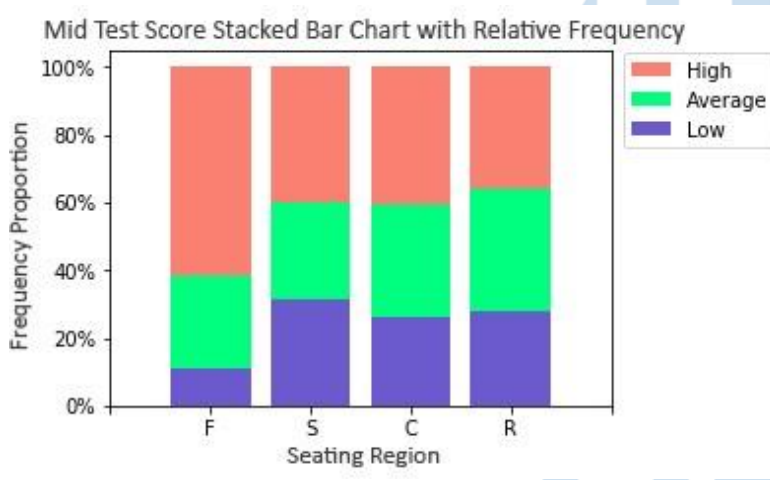

Fig. 6. A sample stacked bar chart with relative frequency for mid test score. Horizontal axis represents the seating regions while the vertical one represents the score.

\section{B. Addressing RQ2: The Questionnaire Survey}

In order to answer RQ2, whether student seating position is driven by the awareness of SP-AP correlation, a survey was developed with three sub research questions on board:

RQ2A What is student preference on seating position in a classroom? If most of the responses prefer the front region compared to others, it might be stated that the seating position is driven with an awareness of that correlation.

RQ2B What factors motivating students to choose the position? If most of the factors are related to the distance between student seating position and the front of the classroom, the seating preference might be derived from the awareness of that correlation.
RQ2C Do students consider that seating position in a classroom may have influence on their academic performance? This is the only direct question asking the students' perspective about that correlation.

RQ2A was also converted to one survey question: among the four regions (see the following figure) which seating region is the most preferable for you?

As proposed in [19], student seating position on the attached figure (Fig. 7) was classified into four regions: front, centre, side, and rear. SP-AP correlation might be considered in selecting the region if front is the most preferred, followed by centre/side, and rear.

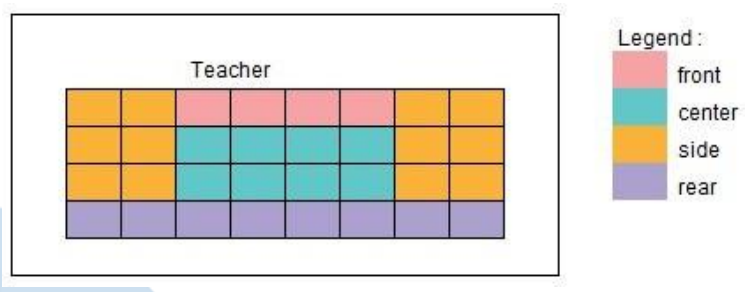

Fig. 7. Displayed figure for R2, depicting seating positions in a classroom. Each colour represents one seating region.

RQ2B was converted to a survey question: "What are the motivating factors for you in choosing seating position in a classroom?". This question is accompanied by some predefined factors to choose from. In which some of them are related to the distance between student seating position and the front of the classroom. The factors were classified into three categories: internal physical, internal non-physical, and external factors. Internal physical factors are derived from respondent's physical state (e.g., hearing and vision limitation). Internal nonphysical factors are derived from respondent's mental state (e.g., interest toward the subject or teaching style). External factors are derived from instances around the respondent (e.g., position of white board, lecturer, window, and door). The detail of these factors (for each category) is summarised in Table III, including whether the factors relate to the distance between student position and the front of the classroom. F1-F4 are the internal physical factors, F5F8 are the internal non-physical factors, and F9-F14 are the external factors. Apart from the predefined factors, our respondents were also allowed to provide some other motivating factors which were not covered in the survey. 
TABLE III. PREDEFINED FACTORS FOR RQ2A

\begin{tabular}{|l|l|l|l|}
\hline ID & Factor & Description & Distance Relation \\
\hline F1 & $\begin{array}{l}\text { Height proportion toward other } \\
\text { students }\end{array}$ & $\begin{array}{l}\text { Respondent is shorter or taller than other } \\
\text { students }\end{array}$ & Yes \\
\hline F2 & Vision limitation & Respondent's vision is limited & Yes \\
\hline F3 & Hearing limitation & Respondent's hearing is limited & Yes \\
\hline F4 & Fatigue level & $\begin{array}{l}\text { Respondent's tiredness prior entering lecture } \\
\text { session }\end{array}$ & Yes \\
\hline F5 & Course interest & $\begin{array}{l}\text { Respondent is interested with given } \\
\text { course material }\end{array}$ & Yes \\
\hline F6 & Teaching-style interest & $\begin{array}{l}\text { Respondent is interested with how lecturer } \\
\text { teaches }\end{array}$ & Yes \\
\hline F7 & Friend & $\begin{array}{l}\text { Respondent's preference is affected by their } \\
\text { friend }\end{array}$ & No \\
\hline F8 & Unexplainable routine & $\begin{array}{l}\text { Respondent always chooses the same } \\
\text { position without knowing their clear } \\
\text { reason }\end{array}$ & No \\
\hline F9 & Door position & $\begin{array}{l}\text { Respondent's preference is affected by door } \\
\text { position }\end{array}$ & No \\
\hline F10 & Window position & $\begin{array}{l}\text { Respondent's preference is affected by } \\
\text { window position }\end{array}$ & No \\
\hline F11 & Air conditioner position & $\begin{array}{l}\text { Respondent's preference is affected by air } \\
\text { conditioner position }\end{array}$ & No \\
\hline F12 & Whiteboard position & $\begin{array}{l}\text { Respondent's preference is affected by } \\
\text { whiteboard position }\end{array}$ & Yes \\
\hline F13 & Projector view position & $\begin{array}{l}\text { Respondent's preference is affected by } \\
\text { projector position }\end{array}$ & $\begin{array}{l}\text { Yespondent's preference is affected by } \\
\text { lecturer position }\end{array}$ \\
\hline F14 & Lecturer position & Yes \\
\hline
\end{tabular}

Unique to RQ2C, it was covered by two survey questions: do you agree that seating position affects academic performance? and what is your opinion on the relationship between students seating position and academic performance?. The first question is followed by a Likert scale to choose from: strongly agree, agree, neutral, disagree, and strongly disagree. The second one is an open-ended question which allows our respondents to express and elaborate their opinion on the relationship between seating position and academic performance.

We released the questionnaire as an online survey, and it was opened for two weeks. The targeted audiences for the survey are undergraduate computing students. There were 126 students participating in the survey. Our respondents were quite diverse in terms of enrolment years, ranging from 2014 to 2017. The respondents are arguably representative given that the total enrolled students for such range is about 500 students. Further, they are arguably balanced in terms of enrollment years given that the survey was offered on at least one compulsory course for each enrolment year.

\section{RQ1 FINDINGS: CORRELATION BETWEEN STUdENT SEATING POSITION AND THEIR ACADEMIC PERFORMANCE}

This section summarises findings from the observational study to answer RQ1, whether there is any correlation between student seating position and their academic performance. Findings from onedimension filtering will be discussed first, followed by findings from two-dimension filtering. The analysis for three-dimension filtering was not performed as some interesting findings had been discovered on the two-dimension filtering. At the end of this section, all findings are generalised to answer RQ1.

\section{A. Findings from One-Dimension Filtering}

According to our observation, no distinctive findings can be gained from one-dimension filtering; the data shows no patterns. One of the possible reasons is that the student characteristics included per analysis is too broad.

\section{B. Findings from Two-Dimension Filtering: Major and Teaching Type}

This subsection covers findings resulted from applying major and teaching type as the filter. It results in four groupings: IT-lecture session, IT-lab session, IS-lecture session, and IS-lab session. In general, according to the seating distribution, all of them shows that centre region is preferred by the students. The centre region is always fully seated in most sessions.

On IT major groupings (IT-lecture session and ITlab session), it is clear that high-performance students are seated in the front region. That region is correlated 
with the highest score in all score metrics (mid test, final test, assignment, and final score) regardless of teaching type and used graph for analysis. The rear region, on the contrary, is packed with the lowperformance student. It has more low-performance students compared to other seating regions.

On IS major, no findings can be gained on lecture session type (IS-lecture session). However, analysis on lab session teaching type (IS-lab session) shows that high performance students are commonly seated at the centre. Further, centre region is more packed after the mid test; some students move from the side region to that region.

\section{Findings from Two-Dimension Filtering: Major and Teaching Session Time}

This subsection covers findings resulted from applying major and teaching session time as the filter. It results in eight groupings: IT-morning, ITafternoon, IT-late afternoon, IT-night, IS-morning, IS-afternoon, IS-late afternoon, and IS-night. Generally speaking, all students prefer to be seated in centre except at the night session where the side region is preferred.

An analysis toward morning sessions and IT students (IT-morning) shows that students who are seated in front tend to achieve high score regardless of the score metrics. Further, students on the side region tend to achieve the low one.

On the late afternoon sessions (IT-late afternoon), the number of IT students who are seated in front is lower than other seating regions'. However, these students commonly have the highest score compared to other students.

Taking the context of IS students, on afternoon sessions (IS-afternoon), front seating region is filled with low performance students instead of the high one. High performance students prefer to be seated on the rear region.

When the sessions are changed to the late afternoon ones (IS-late afternoon), such high performance students are often found in the centre region. Even though its proportion is still lower than those who are seated on the side.

\section{Findings from Two-Dimension Filtering: Teaching Type and Session Time}

This subsection covers findings resulted from applying teaching type and session time as the filter. It results in eight groupings: lecture session-morning, lecture session-afternoon, lecture session-late afternoon, lecture session-night, lab session-morning, lab session-afternoon, lab session-late afternoon, and lab session-night. In general, the centre region is preferred by most students regardless of teaching type and session time.
In the morning (lecture session-morning and lab session-morning), students who seated in the front region tend to get high score $(\mathrm{B}+$ or $\mathrm{A})$ for all score metrics, regardless of teaching type. Further, those who seated in the side region tend to have the low score (lower than $\mathrm{C}$ ).

At afternoon session time (lecture sessionafternoon and lab session-afternoon), high performance students are grouped on the side region on lab session while being seated on the centre region on lecture session.

An analysis on late afternoon session in both lecture session and lab session teaching types (lecture session-late afternoon and lab session-late afternoon) show that highperformance students are often seated in front on that time session; three of four score metrics show the same phenomenon. In terms of quantity, the centre region is preferred on lecture session while the side region is preferred on lab session.

In the night session (lecture session-night and lab session-night), the front region is still occupied by high performance students while the rear one is packed with low performance students. However, this does not mean that the front region is seated by many students. Most of them prefer the centre region, followed by the side and rear regions.

\section{E. Generalised Findings}

In general, the correlation between student seating position and their academic performance occurs in some cases. In addition, three other findings can be deducted:

- IT students who are seated in front commonly have higher score compared to students seated on other regions. This also applies on IS students on morning sessions.

- In the afternoon, high performance students tend to be seated on side region.

- Centre region is preferred by most students according to 59 of 80 analyses.

\section{FINDINGS: STUDENT AWARENESS TOWARD SP- AP CORRELATION}

This section summarises findings from the questionnaire survey to answer RQ2, whether student seating position is driven by the awareness of SP-AP correlation. RQ2A and RQ2B findings will be discussed first, followed by RQ2A findings revisited with RQ2B findings on board. After that, RQ2C findings will be discussed and finally, the generalised findings will be discussed. 


\section{A. RQ2A Findings: Student Seating Preference}

Fig. 8 shows that centre is the most preferred seating region. It is preferred by 67 of 126 respondents. In contrast, front is the least preferred one with 14 of 126 respondents. We could confirm that these findings were match with our teaching experience; where the centre region is frequently filled first and the front region is mostly empty (except the lecturer asks the students to move forward or no other seating regions are available for latecomers).

This means that based on RQ2A, student seating preference might not be driven by the awareness of SP-AP correlation. Front region is the least preferred, while the rear one is the second-most preferred.

\section{B. RQ2B Findings: Motivating Factors in Seating Preference}

The frequency distribution of the motivating factors in classroom seating position among our respondents is presented in Fig. 9. From the figure, we can identify that friend (F7) is the most influential factor for the students in choosing their seating position; it was voted by 83 respondents out of 126 . This could indicate that social aspect has a significant contribution toward seating distribution in a classroom. Other factors, such as air conditioner position (F11), projector screen position (F13), white board position (F12), and personal habit (F8) were also have significant influence in classroom seating position; there were more than 60 respondents voted for these factors. The position of air conditioner in a classroom was quite a surprising factor for us as we never really expected that such factor would be highly influential. Further investigation explained that most of our students tend to avoid seating nearby the air conditioner as often the air temperature was too cold for them. Among the predefined factors, window position (F10) was the least influential factor where only two respondents voted for it. Such finding was not surprising in our study since most windows in our classrooms were covered with curtains.

\section{Seating Preference}

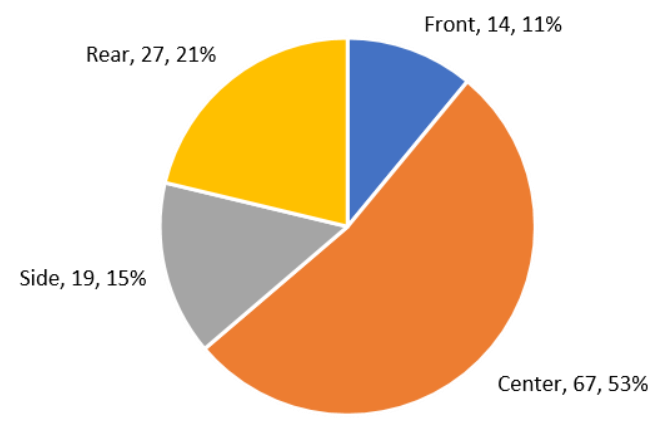

Fig. 8. Seating preference according to our respondents. Centre is the most preferred one, followed by rear, side, and front.

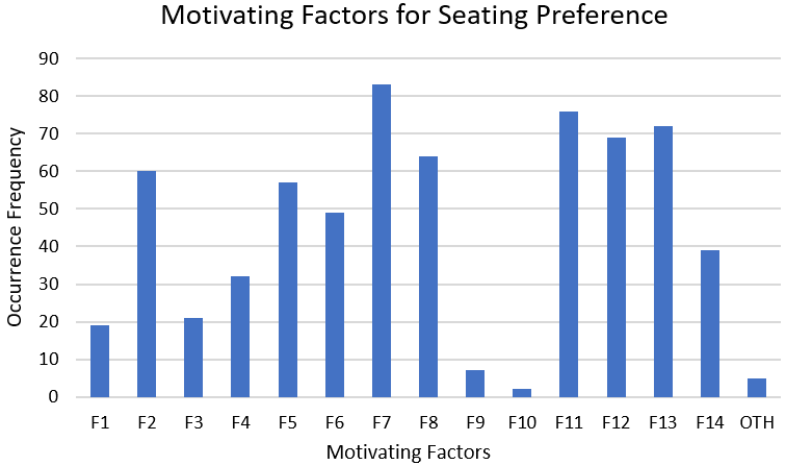

Fig. 9. Occurrence frequencies of motivating factors for seating preferences. The most frequently mentioned factor is friend (F7) while window position (F10) is the least frequently mentioned one.

Apart from the predefined motivating factors, three additional factors were promoted by our respondents: seats availability, previously-saved data on computer, and nervousness. The first two factors fall on external factor category while the last one falls on internal non-physical factor category. All of them are not related to the distance between student position and the front of the classroom. In other words, they are not driven by the awareness of SP-AP correlation. Seats availability was mentioned by two respondents; they argued that seating position in a classroom was influenced by the availability of the seats. Sometimes their preferred seating position was taken by other students and they had to choose other seats. Previously-saved data on computer is mentioned by two respondents. They choose the same seating position each week so that they could use their previously-saved data on the computer that is assigned to such position. It is important to note that this factor only occurs when given classroom is a computer laboratory where each seating position is featured with a computer. Nervousness is mentioned by one respondent, claiming that they cannot focus when lecturer pays attention to them. They choose seating position that is rarely focused by the lecturer.

External factor category yields the highest occurrence frequency, followed by internal nonphysical and physical factor category (see Fig. 10). In other words, it can be stated that students' seating preference is heavily affected by the position of instances around them. Internal physical factors (such as fatigue level) play a small role on such preference. This finding opened a possibility for us to alter our classroom environment in such a manner which potentiality could reshape the distribution of seating position in the class. Further investigation is required to better understand this phenomenon.

If the factors were grouped based on their relation to the correlation between student seating position and their academic performance, more factors with such a relation were discovered (see Fig. 11). Nearly two thirds of the discovered aspects (418 of 655) are 
related to the correlation. Hence, it can be stated that, based on RQ2B, the awareness of that correlation might drive the student seating preference.

\section{Revisiting $R Q 2 A$ Findings with regard to $R Q 2 B$ Findings}

Having RQ2B findings enables deeper understanding of RQ2A findings. The seating preference per motivating factor can be observed. As depicted in Fig. 12, centre is still the most preferred one. It was voted by most respondents in all factors except $\mathrm{F} 10$ - where front and side seating region are preferred. In other words, it can be stated that all motivating factors except window location (F10) lead students to sit on centre region.

In contrast, the least preferred seating region varies among considered factors. Front is least preferred when respondents consider height proportion toward other students (F1), fatigue level (F4), friend (F7), door position (F9), or air conditioner position (F11). Centre is least preferred when window position (F10) is considered. Side is least preferred when respondents consider teachingstyle interest (F6), unexplained routine (F8), air conditioner position (i.e., as our study is conducted in a tropical country) (F11), whiteboard position (F12), projector view position (F13), or lecturer position (F14). Rear is least preferred when vision limitation (F2), hearing limitation (F3), course interest (F5), teaching-style interest (F6), door position (F9), or window position (F10) is considered.

This revisit shows that, regardless of the considered factors, RQ2A still shows that the student seating preference might not be driven by the awareness of SP-AP correlation.

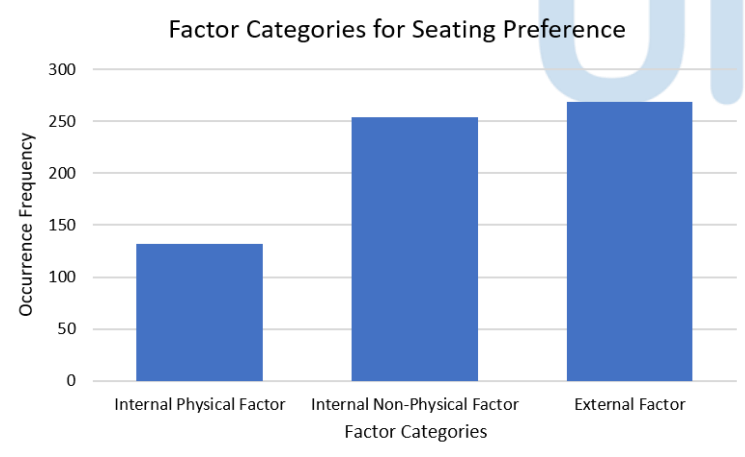

Fig. 10. Occurrence frequencies of factor categories for seating preference. The frequency of each category is resulted by summing all frequencies of covered factors.

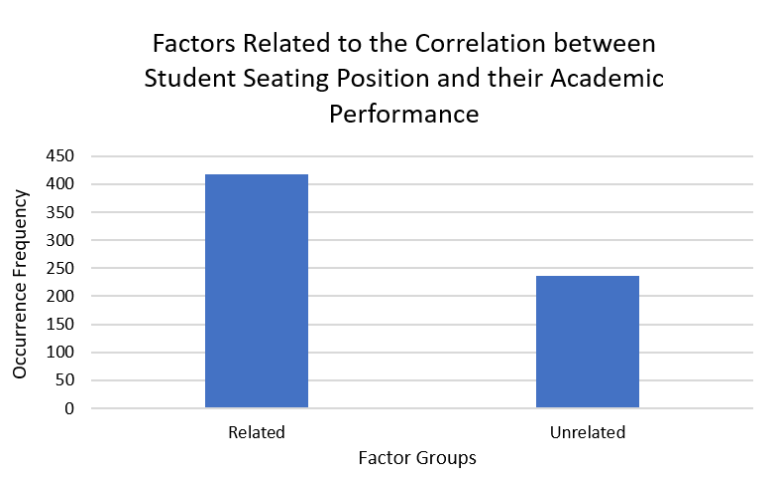

Fig. 11. Occurrence frequencies of factors, grouped based on the relation to the correlation between student seating position and their academic performance. The frequency of each group is resulted by summing all frequencies of covered factors.

Seating Preference per Motivating Factor

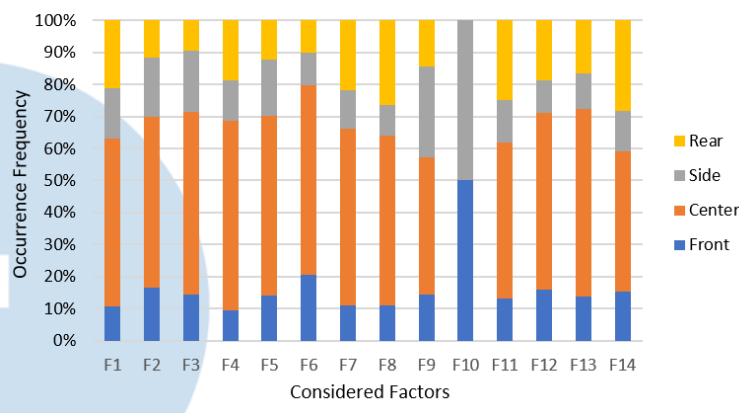

Fig. 12. Seating preference per motivating factor. The proportion of each seating region is resulted by dividing its occurrence frequency with total frequencies of all regions (where only respondent answers that consider such factor are included).

\section{RQ2C Findings: Student Perspective Regarding} Seating Position Affects Academic Performance

Fig. 13 shows that most respondents (46 of 126) prefer to be neutral toward a statement that claims seating position affects academic performance. Such neutral opinion is also supported by the fact that, when each option is converted to scale (where strongly agree $=2$, agree $=1$, neutral $=0$, disagree $=$ 1 , and strongly disagree $=-2$ ), mean score from respondent answers $(0.0158)$ is still extremely close to neutral (0).

The statement claiming that seating position affects academic performance is agreed according to six rationales, which summary and occurrence frequency can be seen in Table. For convenience, those rationales are sorted in descending order according to their frequency. In most occasions, students argued that being closer to the front of classroom enhances concentration and the position of external factors affects student concentration. 


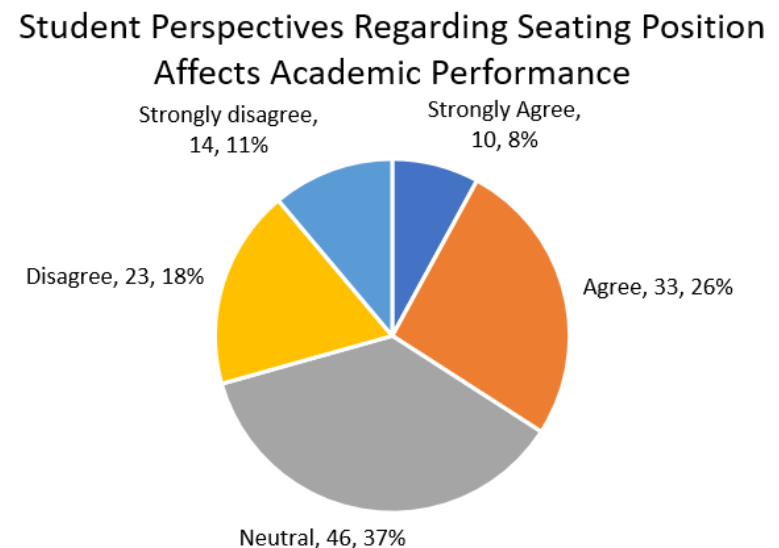

Fig. 13. Student perspectives regarding seating position affects academic performance. Most of them prefer to be neutral.

TABLE IV. RATIONALES BACKED UP RESPONDENT AGREEMENT

\begin{tabular}{|l|l|l|}
\hline ID & Rationale & $\begin{array}{l}\text { Frequenc } \\
\text { y (agree }+ \\
\text { strongly } \\
\text { agree) }\end{array}$ \\
\hline A1 & $\begin{array}{l}\text { The more ahead you are, the more } \\
\text { focused you will be. }\end{array}$ & $15+5$ \\
\hline A2 & $\begin{array}{l}\text { The position of external factors } \\
\text { affects student concentration. }\end{array}$ & $12+2$ \\
\hline A3 & $\begin{array}{l}\text { Avoiding lecturer's focused } \\
\text { region is necessary to boost } \\
\text { concentration performance (since } \\
\text { those students are shy). }\end{array}$ & $2+1$ \\
\hline A4 & $\begin{array}{l}\text { Convenient seating position leads } \\
\text { to better learning performance. }\end{array}$ & $2+0$ \\
\hline A5 & $\begin{array}{l}\text { The learning performance of each } \\
\text { student is affected by various } \\
\text { factors related to seating } \\
\text { preference. }\end{array}$ & $2+0$ \\
\hline A6 & $\begin{array}{l}\text { Fengshui (i.e., Chinese belief } \\
\text { about the relation between luck } \\
\text { and position). }\end{array}$ & $0+1$ \\
\hline
\end{tabular}

Some respondents disagree with the effect of seating position toward academic performance according to five rationales.

Table summarises those rationales, including their occurrence frequency. Generally speaking, most of them argued that academic performance depends on students' effort instead of seating position.

\section{E. Generalised Findings}

Findings from the three sub research questions (RQ2A, RQ2B, and RQ2C) show no clear generalised findings; each of those questions leads to different direction. However, we can say that student seating position can be driven by the awareness of SP-AP correlation with some motivating factors on board.

\section{CONCLUSION AND FUTURE WORK}

This paper measures the correlation between student seating position and their academic performance via an observational study involving 426 computer science students over one academic semester. Further, a questionnaire survey regarding student awareness about that correlation in selecting their seating position is also performed to suggest further necessary actions. Our research shows that the correlation only exists on some circumstances and the seating preference can be driven by the awareness of that correlation with some motivating factors on board. Hence, it is important to analyse the class circumstances and the student motivating factors prior performing further actions.

Our study has two limitations and those can result in further research. First, the findings are based on only a dataset and thus might not be generalisable. We plan to replicate our study on other datasets and revalidate the findings. Second, some students might be seated in a particular position due to the unavailability of their first preferred seating region, and this might affect the findings. Another study without such a constraint is necessary to strengthen the current findings.

TABLE V.RATIONALES BACKED UP RESPONDENT DISAGREEMENT

\begin{tabular}{|l|l|l|}
\hline ID & Rationale & $\begin{array}{l}\text { Frequency } \\
\text { (disagree } \\
+ \text { strongly } \\
\text { disagree }\end{array}$ \\
\hline D1 & $\begin{array}{l}\text { Academic performance purely } \\
\text { depends on students' effort, not } \\
\text { seating position. }\end{array}$ & $18+9$ \\
\hline D2 & $\begin{array}{l}\text { The learning performance of each } \\
\text { student is affected by various } \\
\text { factors but those factors are not } \\
\text { related to seating position. }\end{array}$ & $2+2$ \\
\hline D3 & $\begin{array}{l}\text { Seating position only affects } \\
\text { student convenience. Yet, such } \\
\text { convenience is not related to } \\
\text { academic performance. }\end{array}$ & $1+1$ \\
\hline D4 & $\begin{array}{l}\text { Teaching method is far more } \\
\text { prominent to determine academic } \\
\text { performance than seating position. }\end{array}$ & $1+1$ \\
\hline
\end{tabular}

This study inspires other project within our department to record student attendance in a classroom in a form of photograph $[25,26]$. With the assistance of advancements in face recognition and row detection, we envision to automate the procedure in recording student seating position.

\section{ACKNOWLEDGMENT}

The authors would like to thank Maranatha Christian University for supporting this research. 


\section{REFERENCES}

[1] D. Insa, J. Silva and S. Tamarit, "Where You Sit MattersHow Classroom Seating Might Affect Marks," in Proceedings of the 2016 ACM Conference on Innovation and Technology in Computer Science Education - ITiCSE '16, Arequipa, 2016.

[2] D. W. Levine, E. C. O'Neal, S. G. Garwood and P. J. McDonald, "Classroom Ecology: The Effects of Seating Position on Grades and Participation," Personality and Social Psychology Bulletin, vol. 6, p. 409-412, 1980.

[3] A. McGowan, P. Hanna, D. Greer and J. Busch, "Learning to Program: Choose Your Lecture Seat Carefully!," in Proceedings of the 2017 ACM Conference on Innovation and Technology in Computer Science Education - ITiCSE '17, 2017.

[4] K. Zomorodian, M. Parva, I. Ahrari, S. Tavana, C. Hemyari, K. Pakshir, P. Jafari and A. Sahraian, "The Effect of Seating Preferences of The Medical Students on Educational Achievement," Medical Education Online, vol. 17, p. 10448, 2012.

[5] K. K. Perkins and C. E. Wieman, "The Surprising Impact of Seat Location on Student Performance," The Physics Teacher, vol. 43, p. 30-33, 2005.

[6] M. E. Benedict and J. Hoag, "Seating Location in Large Lectures: Are Seating Preferences or Location Related to Course Performance?," Journal of Economic Education, vol. 35, p. 215-231, 2004.

[7] S. Kalinowski and M. L. Taper, "The Effect of Seat Location on Exam Grades and Student Perceptions in an Introductory Biology Class," Journal of College Science Teaching, vol. 36, p. 54-57, 2007.

[8] M. Meeks, T. Knotts, K. James, F. Williams, J. Vassar and A. Wren, "The Impact of Seating Location and Seating Type on Student Performance," Education Sciences, vol. 3, p. 375-386, 2013.

[9] U. Fuller, C. Riedesel, E. Thompson, C. G. Johnson, T. Ahoniemi, D. Cukierman, I. Hernán-Losada, J. Jackova, E. Lahtinen, T. L. Lewis and D. M. Thompson, "Developing a computer science-specific learning taxonomy," in Working group reports on ACM International Conference on Innovation and Technology in Computer Science Education, Dundee, 2007.

[10] Simon, B. Cook, J. Sheard, A. Carbone and C. Johnson, "Academic integrity perceptions regarding computing assessments and essays," in The 10th Annual Conference on International Computing Education Research, New York, New York, USA, 2014.

[11] Simon, B. Cook, J. Sheard, A. Carbone and C. Johnson, "Academic integrity: differences between computing assessments and essays," in The 13th Koli Calling International Conference on Computing Education Research, Koli, 2013.

[12] C. I. Brooks and J. L. Rebeta, "College Classroom Ecology: The Relation of Sex of Student to Classroom Performance and Seating Preference," Environment and Behavior, vol. 23, p. 305-313, 1991.

[13] J. L. Rebeta, C. I. Brooks, J. P. O'brien and G. A. Hunter, "Variations in Trait-Anxiety and Achievement Motivation of College Students as a Function of Classroom Seating Position," The Journal of Experimental Education, vol. 61, p. 257-267, 1993.

[14] J. M. Burda and C. I. Brooks, "College Classroom Seating Position and Changes in Achievement Motivation over a Semester," Psychological Reports, vol. 78, p. 331-336, 1996.

[15] R. Wannarka and K. Ruhl, "Seating arrangements that promote positive academic and behavioural outcomes: a review of empirical research," Support for Learning, vol. 23, p. 89-93, 2008.

[16] J. A. Daly and A. Suite, "Classroom Seating Choice and Teacher Perceptions of Students," Journal of Experimental
Education, vol. 50, p. 64-69, 1981.

[17] P. F. Totusek and A. Q. Staton-Spicer, "Classroom Seating Preference as a Function of Student Personality," Journal of Experimental Education, vol. 50, p. 159-163, 1982.

[18] S. I. Lindquist and J. P. McLean, "Daydreaming and its correlates in an educational environment," Learning and Individual Differences, vol. 21, p. 158-167, 2011.

[19] T. Kitagawa, "The latent four-zone structure in classroom seating space," Japanese Psychological Research, vol. 40, p. 40-46, 1998.

[20] A. E. Budiman and O. Karnalim, "Automated hints generation for investigating source code plagiarism and identifying the culprits on in-class individual programming assessment," Computers, vol. 8, p. 11, 2019.

[21] N. Hastings and J. Schwieso, "Tasks and tables: the effects of seating arrangements on task engagement in primary classrooms," Educational Research, vol. 37, p. 279-291, 1995.

[22] J. C. McCorskey and R. W. McVetta, "Classroom seating arrangements: Instructional communication theory versus student preferences," Communication Education, vol. 27, p. 99-111, 1978.

[23] M. M. Haghighi and M. B. M. Jusan, "The impact of classroom settings on students' seat-selection and academic performance," Indoor and Built Environment, vol. 24, p. 280288, 2015.

[24] I. Olkin and A. R. Sampson, "Multivariate Analysis: Overview," International Encyclopedia of the Social \& Behavioral Sciences, p. 10240-10247, 2001.

[25] S. Budi, O. Karnalim, E. D. Handoyo, S. Santoso, H. Toba, H. Nguyen and V. Malhotra, "IBAtS-Image Based Attendance System: A Low Cost Solution to Record Student Attendance in a Classroom," in 2018 IEEE International Symposium on Multimedia (ISM), 2018.

[26] O. Karnalim, S. Budi, S. Santoso, E. D. Handoyo, H. Toba, H. Nguyen and V. Malhotra, "Face-face at classroom environment: Dataset and exploration," in 2018 Eighth International Conference on Image Processing Theory, Tools and Applications (IPTA), 2018. 